\title{
USING AND ABUSING ECONOMIC THEORY
}

\section{PRELIMINARY; COMMENTS WELCOME}

the latest version of this paper, and related material, will be at http://www.paulklemperer.org

Paul Klemperer

Nuffield College, Oxford University, Oxford OX1 1NF, England

Int Tel: +44 1865278588 Int Fax: +44 1865278557

email: paul.klemperer@economics.ox.ac.uk

This draft: December 2002

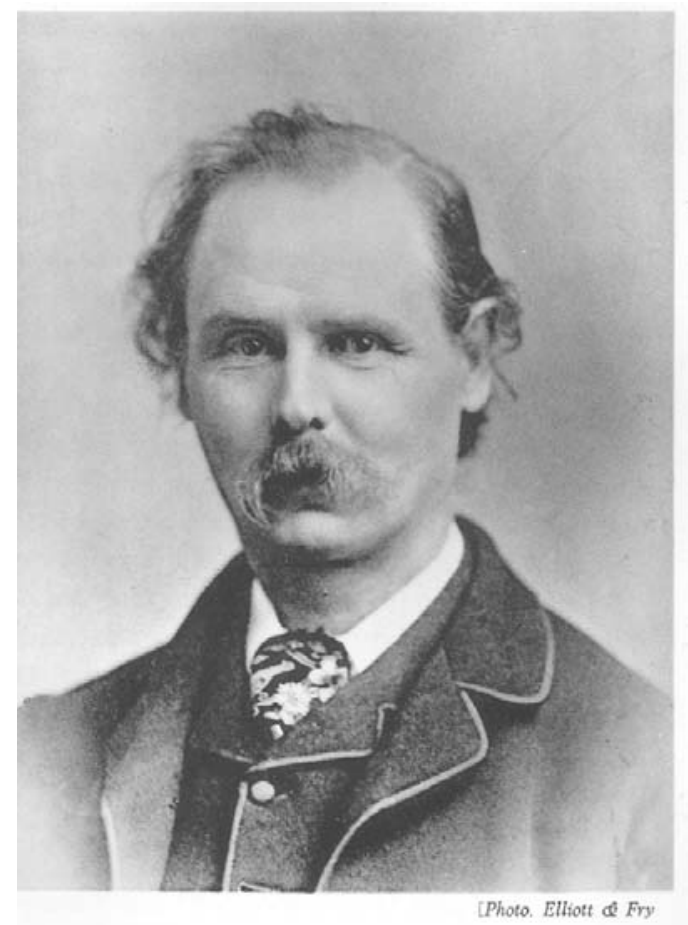

2002 Alfred Marshall Lecture to the European Economic Association

Economic theory is often abused in practical policy-making. There is frequently excessive focus on sophisticated theory at the expense of elementary theory; too much economic knowledge can sometimes be a dangerous thing. Too little attention is paid to the wider economic context, and to the dangers posed by political pressures. Superficially trivial distinctions between policy proposals may be economically significant, while economically irrelevant distinctions may be politically important. I illustrate with some disastrous government auctions, but also show the value of economic theory.

JEL Nos: A11 (role of economics), B4 (economic methodology), D44 (auctions), L96 (telecommunications).

Acknowledgements: I advised the UK Government on the design of its "3G" mobile-phone auction, and I am a Member of the UK Competition Commission, but the views expressed in this paper are mine alone. I do not intend to suggest that any of the behavior discussed below violates any applicable rules or laws. This paper has been improved by an enormous number of helpful comments, including from...

Keywords:

(C) Paul Klemperer, 2002 


\section{Introduction}

It is a great honor to present the Alfred Marshall lecture. ${ }^{1}$ For half a century or more after the publication of his Principles (1890), it was routinely asserted of economic ideas that "they're all in Marshall". Of course, that is no longer true of the theory itself. But Marshall was also very concerned with applying economics, and when we think about how to use the theory, the example that Marshall set still remains a valuable guide. Today, therefore, I want to use some of Marshall's views, and my own experience in auction design, to discuss the use (and abuse) of economic theory.

Although the most elegant mathematical theory is often the most influential, it may not be the most useful for practical problems. Marshall (1906) famously stated that "a good mathematical theorem dealing with economic hypotheses [is] very unlikely to be good economics", and continued by asserting the rules "(1) Translate [mathematics] into English; (2) Then illustrate by examples that are important in real life; (3) Burn the mathematics; (4) If you can't succeed in 2, burn 1"! Certainly this view now seems extreme, but it is salutary to be reminded that good mathematics need not necessarily be good economics. To slightly update Marshall's rules, if we can't (1) offer credible intuition and (2) supply empirical (or perhaps case-study or experimental) evidence, we should (4) be cautious about applying the theory in practice. ${ }^{2}$

Furthermore, when economics is applied to policy, proposals need to be robust to the political context in which they are intended to operate. Too many economists excuse their practical failure by saying "the politicians (or bureaucrats) didn't do exactly what I recommended". Just as medical practitioners must allow for the fact that their patients may not take all the pills they prescribe, or follow all the advice they are given, so economics practitioners need to foresee political and administrative pressures and make their plans robust to changes that politicians, bureaucrats, and lobbyis ts are likely to impose. And in framing proposals, economists must recognize that policies that seem

\footnotetext{
${ }^{1}$ This is the text of the 2002 Alfred Marshall Lecture of the European Economic Association, given at its Annual Congress, in Venice.

I gave a similar lecture at the 2002 Colin Clark Lecture of the Econometric Society, presented to its Annual Australasian Meeting. Like Marshall, Clark was very involved in practical economic policy making. He stressed the importance of quantification of empirical facts which, I argue below, is often underemphasized by modern economic theorists.

Similar material also formed the core of the biennial 2002 Lim Tay Boh Lecture in Singapore. Lim was another very distinguished economist (and Vice-Chancellor of the National University of Singapore), who also made significant contributions to policy, as an advisor to the Singapore Government.

Finally, some of these ideas were presented in the Keynote Address to the 2002 Portuguese Economic Association's 2002 meetings.

I am very grateful to all those audiences for helpful comments.

${ }^{2}$ I mean cautious about the theory. Not dismissive of it. And (3) seems a self-evident mistake, if only because of the need for efficient communication among, and education of, economists, let alone the possibilities for further useful development of the mathematics.
} 
identical, or almost identical, to them may seem very different to politicians, and vice versa.

Some academics also need to widen the scope of their analyses beyond the confines of their models which, while elegant, are often short on real world detail. Marshall always emphasised the importance of a deep "historical knowledge of any area being investigated and referred again and again to the complexity of economic problems and the naivety of simple hypotheses." narrowly-focused theories instead of experienced people with a good knowledge of the wider context can sometimes lead to disaster.

One might think these lessons scarcely needed stating - and Marshall certainly understood them very well - but the sorry history of "expert" advice in some recent auctions shows that they bear repetition. So although the lessons are general ones, I will illustrate them using auctions and auction theory: Auction theory is often held up as a triumph of the application of economic theory to economic practice, but it has not, in truth, been an unalloyed success. For example, while the European and Asian 3G spectrum auctions famously raised over 100 billion euros in total revenues, Hong Kong's, Austria's, the Netherlands', and Switzerland's auctions were catastrophically badly run yielding only a quarter or less of the per capita revenues earned elsewhere - and economic theorists deserve some of the blame. ${ }^{4,5}$ Other countries' auctions worked through good luck rather than good design, while bidders advised by so-called experts in auction theory pursued strategies that cost them billions of euros. Many of these failures could have been avoided if the lessons had been learnt: pay more attention to elementary theory, to the wider context of the auctions, and to political pressures - and pay less attention to sophisticated mathematical theory. ${ }^{6}$

\footnotetext{
${ }^{3}$ Sills (1968) p.28. An attractively written appreciation of Marshall and his work is in Keynes (1933).

${ }^{4}$ We take the governments' desire for high revenue as given, and ask how well the auctions met this objective. While an efficient allocation of licences was most governments' first priority, there is no clear evidence of any differences between the efficiencies of different countries' allocations, so revenues were seen as the measure of success. (Binmore and Klemperer (2002, Section 2) argues governments were correct to make revenue a priority because of the substantial deadweight losses of raising government funds by alternative means, and because the revenues were one-time sunk costs for firms so should be expected to have only limited effects on firms' subsequent investment and pricing behavior.)

5 The six European auctions in year 2000 yielded 100 (Austria), 615 (Germany), 240 (Italy), 170 (Netherlands), 20 (Switzerland), and 650 (UK) euros per capita for very similar properties. True, valuations fell during the year as the stockmarkets also fell, but Klemperer (2002a) details a variety of evidence that valuations ranged from 300-700 euros per capita in all of these auctions. Klemperer (2002a) gives a full description of all nine west European $3 \mathrm{G}$ auctions.

${ }^{6}$ Another topical example of overemphasis on sophisticated theory at the expense of elementary theory is European merger policy's heavy focus on the 'coordinated' effects that may be facilitated by a merger (and about which we have learnt from repeated game theory) and, at the time of writing, relative lack of concern about the more straightforward 'unilateral' effects of mergers (which can be understood using much simpler static game theory). (As a Member of the U.K. Competition Commission, I stress that this criticism does not apply to U.K. policy!)
} 
Of course, mathematical theory, even when it has no direct practical application, is not merely beautiful. It can clarify the central features of a problem, provide useful benchmarks and starting points for analysis and - especially - show the deep relationships between problems that are superficially unconnected. Thus, for example, the sophisticated tools of auction theory that have sometimes been abused in practical contexts turn out to have valuable applications to problems that, at first blush, do not look like auctions.

Section 2 briefly discusses what is often taken to be the "standard auction theory", before discussing its real relevance. Sections 3-5 illustrate its abuse using examples from the Asian and European $3 \mathrm{G}$ auctions, and discuss the broader lessons that can be drawn from these misapplications. Section 3 is in large part based on Klemperer (2000b, 2002ae) where many additional details can be found - and this section may be skipped by readers familiar with that material - but the other sections make different points using additional examples. Section 6 illustrates how the same concepts that are abused can have surprisingly valuable uses in different contexts. Section 7 concludes.

\section{The Received Auction Theory}

The core result that everyone who studies auction theory learns is the remarkable Revenue Equivalence Theorem (RET). ${ }^{7}$ This tells us, subject to some reasonablesounding conditions, that all the standard (and many non-standard) auction mechanisms are equally profitable for the seller, and that buyers are also indifferent between all these mechanisms.

If that were all there was to it, auction design would be of no interest. But of course the RET rests on a number of assumptions. Probably the most influential piece of auction theory apart from the RET is Milgrom and Weber's (1982) remarkable paper - it is surely no coincidence that this is also perhaps the most elegant piece of auction theory apart from those associated with the RET. Milgrom and Weber's seminal analysis relaxes the assumption that bidders have independent private information about the value of the object for sale, and instead assumes bidders' private information is affiliated. This is

\footnotetext{
${ }^{7}$ The RET is due in an early form to Vickrey (1961), and in its full glory to Myerson (1981), Riley and Samuelson (1981), and others. A typical statement is "Assume each of a given number of risk-neutral potential buyers has a privately-known signal about the value of an object, independently drawn from a common, strictly increasing, atomless distribution. Then any auction mechanism in which (i) the object always goes to the buyer with the highest signal, and (ii) any bidder with the lowest feasible signal expects zero surplus, jields the same expected revenue (and results in each bidder making the same expected payment as a function of her signal)."

Klemperer (1999) gives an elementary introduction to auction theory, including a simple exposition, and further discussion, of the RET.
} 
similar to assuming positive correlation, ${ }^{8}$ and under this assumption they show that ordinary ascending auctions are more profitable than standard (first-price) sealed-bid auctions, in expectation.

Milgrom and Weber's beautiful work is undoubtedly an important piece of economic theory and it has been enormously influential. ${ }^{9}$ As a result, many economists leave graduate school "knowing" two things about auctions. First, that if bidders' information is independent then all auctions are equally good, and second, that if information is affiliated (which is generally the plausible case) the $n$ the ascending auction maximises the seller's revenue. ${ }^{10}$

But is this correct?

\section{Relevance of the Received Theory}

Marshall's (updated) tests are a good place to start. The value of empirical evidence needs no defense, while examining the plausibility of an intuition helps check whether an economic model provides a useful caricature of the real world, or misleads us by absurdly exaggerating particular features of it. ${ }^{11}$

The intuition behind the exact RET result cannot, to my knowledge, be explained in words that are both accurate and comprehensible to lay people. Anyone with the technical skill to understand any verbal explanation would probably do so by translating the words back into the mathematical argument. But it is easier to defend the weaker claim that it is ambiguous which of the two most common auction forms is superior: it is easy to explain that participants in a sealed-bid auction shade their bids below their values (unlike in an ascending auction), but that the winner determines the price (unlike in an ascending auction), so it is not hard to be convincing that there is no clear reason why either auction should be more profitable than the other. This is not quite the same as arguing that the standard auction forms are approximately similarly profitable, but the approximate validity of the RET (under its key assumptions) in fact seems consistent with the available evidence. (Some would say that the mere fact that both the ascending auction and the sealed-bid auction are commonly observed in practice is evidence that neither is always superior.) So the "approximate RET" seems a reasonable claim in

\footnotetext{
${ }^{8}$ It is actually a stronger assumption, but it is probably typically approximately satisfied.

${ }^{9}$ Not only is the concept of affiliation important in applications well beyond auction theory (see section 6) but this paper was also critical to the development of auction theory, in that it introduced and analysed a general model including both private and common value components.

${ }^{10}$ Or, to take just one very typical example from a current academic article "The one useful thing that our single unit auction theory can tell us is that when bidders' [signals] are affiliated ... the English [i.e. ascending] auction should be expected to raise the most revenue".

${ }^{11}$ Whether the intuition need be non-mathematical, or even comprehensible to lay people, depends on the context, but we can surely have greater confidence in predicting agents' actions when the agents concerned understand the logic behind them, especially when there are few opportunities for learning.
} 
practice, and it then follows that issues assumed away by the RET's assumptions should be looked at to choose between the standard auction forms. These issues should include not just those made explicitly in the statement of the theorem, e.g., bidders are symmetric and risk-neutral, but also those that are implicit, e.g., bidders share common priors and play non-cooperative Nash equilibrium, or semi-implicit, e.g., the numbers and types of bidders are independent of the auction form.

However, as already noted, much attention has focused on just one of the RET's assumptions, namely independence of the bidders' information, and the theoretical result that if information is non-independent (affiliated) then ascending auctions are more profitable than first-price sealed-bid auctions. There is no very compelling intuition for this result. The verbal explanations that are given are unconvincing and/or misleading, or worse. The most commonly given "explanation" is that ascending auctions allow bidders to be more aggressive, because their "winner's curses" are reduced, ${ }^{12}$ but this argument is plain wrong: the winner's curse is only a feature of common-value auctions, but common values are neither necessary nor sufficient for the result. ${ }^{13}$

A better explanation of the theoretical result is that bidders' profits derive from their private information, and the auctioneer can profit by reducing that private information. ${ }^{14}$ An ascending auction reveals the information of bidders who drop out early, so partially reveals the winner's information (if bidders' information is correlated), and uses that information to set the price (through the runner-up's bid), whereas the price paid in a sealed-bid auction cannot use that information. Since the ascending and sealedbid auctions are revenue-equivalent absent any correlation (i.e., with independent signals), and provided the runner-up's bid responds to the additional information that an ascending auction reveals in the appropriate way (which it does when information is

\footnotetext{
12 The "winner's curse" reflects the fact that winning an auction suggests one's opponents have pessimistic views about the value of the prize, and bidders must take this into account by bidding more conservatively than otherwise.

${ }^{13}$ The result applies with affiliated private values, in which bidders' values are unaffected by others' information, so there is no winner's curse, and the result does not apply to independent-signal commonvalue auctions which do suffer from the winner's curse. (Where there is a winner's curse, the theory behind the argument is that bidders' private information can be inferred from the points at which they drop out of an ascending auction, so less "bad news" is discovered at the moment of winning than is discovered in winning a sealed-bid auction, so bidders can bid more aggressively in an ascending auction. But this assumes that bidders' more aggressive bidding more than compensates for the reduced winner's curse in an ascending auction - in independent-signal common-value auctions it exactly compensates, which is why there is no net effect, as the RET proves.)

In fact, many experimental and empirical studies suggest bidders fail to fully account for winner's curse effects, so these effects may in practice make sealed-bid auctions more profitable than ascending auctions!

${ }^{14}$ Absent private information, the auctioneer would sell to the bidder with the highest expected valuation at that expected valuation, and bidders would earn no rents. The more general result that, on average, the selling price is increased by having it depend on as much information as possible about the value of the good, is Milgrom and Weber's (1982, 2000) Linkage Principle. However, in more recent work, Perry and Reny (1999) show that the Principle applies less generally (even in theory) than was thought.
} 
affiliated), this effect makes the ascending auction the more profitable. Of course, this argument is obviously still incomplete, ${ }^{15,16}$ and even if it were fully convincing, it would depend on the exact RET applying - which seems a very strong claim.

Furthermore, before relying on any theory mattering in practice, we need to ask: what is the likely order of magnitude of the effect? In fact, numerical analysis suggests the effects of affiliation are often tiny, even when bidders who exactly fit the assumptions of the theory compute their bids exactly using the theory. Riley and Li (1997) analyse equilibrium in a natural class of examples and show that the revenue difference between ascending and first-price auction is very small unless the information is very strongly affiliated: when bidders' values are jointly normally distributed, bidders' expected rents are about $10 \%(20 \%)$ higher in a sealed-bid auction than in an ascending auction even for correlation coefficients as high as $0.3(0.5)$. So these results suggest affiliation could explain why a 3G spectrum auction earned, e.g., 640 rather than 650 euros per capita when bidders' valuations were 700 euros per capita. But the actual range was from just 20 (twenty) to 650 euros per capita! Riley and Li also find that that even with very strong affiliation, other effects, such as those of asymmetry, are more important and often reverse the effects of affiliation, even taking the numbers of bidders, non-cooperative behaviour, common priors, etc., as given. ${ }^{17}$ This kind of quantitative analysis surely deserves more attention than economists often give it.

\footnotetext{
15 Revealing more information clearly need not necessarily reduce bidders' profits (if bidders' information is negatively correlated, the contrary is typically true), the conditions that make the ascending price respond correctly to the additional information revealed are quite subtle, and nor does the argument say anything about how affiliation affects sealed bids. Indeed there are simple and not unnatural examples with the "wrong kind" of positive correlation in which the ranking of auctions' revenues is reversed (see Bulow and Klemperer, forthcoming), and Perry and Reny (1999) also show the trickiness of the argument by demonstrating that the result only holds for single-unit auctions. A more complete verbal argument for the theoretical result is given in Klemperer (1999, Appendix C), but it is very hard (certainly for the layman).

16 Another loose intuition is that in an ascending auction each bidder acts as if he is competing against an opponent with the same valuation. But in a sealed-bid auction a bidder must outbid those with lower valuations. With independent valuations, the RET applies. But if valuations are affiliated, a lower valuation bidder has a more conservative estimate of his opponent's valuation and therefore bids more conservatively. So a bidder in a sealed-bid auction attempting to outbid lower-valuation bidders will bid more conservatively as well. But this argument also rests on the RET applying exactly, and even so several steps are either far from compelling (for example, the optimal bid against a more conservative opponent is not always to be more conservative), or very non-transparent.

${ }^{17}$ An easier numerical example than Riley and Li's assumes bidder $i$ 's value is $v_{i}=\theta+t_{i}$, in which $\theta$ and the $t_{i}$ 's are independent and uniform on [0,1], and $i$ knows only $v_{i}$. With two bidders, expected revenue is $14 / 18$ in a first-price sealed-bid auction and 15/18 in an ascending auction, so bidder rents are $7 / 18$ and $6 / 18$ respectively (though with $n$ bidders of whom $n / 2$ each win a single object, as $n \rightarrow \infty$ bidder rents are $42 \%$ higher in the sealed-bid auction).

With very extreme affiliation, an auctioneer's profits may be more sensitive to the auction form. Modifying the previous example so that there are two bidders who have completely diffuse priors for $\theta$, bidder rents are fifty percent higher in a first-price sealed-bid auction than in an ascending auction (see Klemperer, 1999 Appendix D), and Riley and Li's example yields a similar result for correlation coefficients around .9 (when bidder rents are anyway small). These examples assume private-values. Auctioneers' profits may also be more sensitive to auction form with common-values and, in the previous
} 
Finally, all the previous discussion is in the context of single-unit auctions. Perry and Reny (1999) show that the result about affiliation does not hold - even in theory - in multi- unit auctions. ${ }^{18}$

Given all this, it is unsurprising that there is no empirical evidence (that I am aware of) that argues the affiliation effect is important. ${ }^{19,20}$

So there seems no strong argument to expect affiliation to matter much in most practical applications; independence is not the assumption of the RET that most needs relaxing.

The theory that really matters most for auction design is just the very elementary undergraduate economics of relaxing the implicit and semi-implicit assumptions of the RET about (fixed) entry and (lack of) collusion (see Klemperer, 2002b). ${ }^{21}$ The intuitions are (as Marshall says they should be) easy to explain - we will see that it is clear that bidders are likely to understand and therefore to follow the undergraduate theory. By contrast the intuition for affiliation gives no sense of how bidders should compute their bids, and the calculations required to do so optimally require considerable mathematical sophistication and are sensitive to the precise assumptions bidders make about the "prior" distributions from which their and others' private information is drawn. Of course, this does not mean agents cannot intuitively make approximately optimal decisions (Machlup, 1946; Friedman, 1953), and individual agents need not understand the intuitions behind equilibrium group outcomes. But we can be more confident in predicting that agents will

extreme-affiliation model with diffuse priors on $\theta$, if bidders' signals are $v_{i}$ and the true common value is $\theta$, bidders' rents are twice as high in the sealed-bid auction as in the ascending auction. But, with common values, small asymmetries between bidders are very much more important than affiliation (see Klemperer (1998), Bulow and Klemperer (2002)). Moreover, we will see that other effects also seem to have been quantitatively much more important in practice than affiliation is even in any of these theoretical examples. 18 The RET, also, only generalizes to a limited extent to multi-unit auctions.

${ }^{19}$ For example, empirical evidence about timber sales suggests rough revenue equivalence, or even that the sealed-bid auction raises more revenue given the number of bidders (Hansen (1986), Mead and Schneipp (1989), Paarsch (1991), Rothkopf and Engelbrecht-Wiggans (1993), Haile (1996)) though information is probably affiliated. The experimental evidence (see Kagel and Roth, 1995 and Levin, Kagel, and Richard, 1996) is also inconclusive about whether affiliation causes any difference between the revenues from ascending and sealed-bid auctions.

${ }^{20}$ Like Marshall, Colin Clark (1939) emphasised the importance of quantification and real-world facts (see note 1), writing "I have .. left my former colleagues in the English Universities .. with dismay at their continued preference for the theoretical .. approach to economic problems. Not one in a hundred .. seems to understand [the need for] the testing of conclusions against .. observed facts..." "..The result is a vast output of literature of which, it is safe to say, scarcely a syllable will be read in fifty years' time." I think he would be pleased that an academic from an English University is quoting his syllables well over fifty years after he wrote them.

${ }^{21}$ Risk-aversion and asymmetries (even absent entry issues) also arguably matter more than affiliation (and usually have the opposite effect). It is striking that Maskin and Riley's (1984, 1999) important papers on these topics (see also Matthews, 1983, etc.) failed to have the same broad impact as Milgrom and Weber's work on affiliation. 
make decisions whose logic is very clear, especially in one-off events such as many auctions are.

Not surprisingly, practical examples of the undergraduate theory are easy to give (as Marshall also insists). But there is no elegant theory applying to the specific context of auctions; such theory is unnecessary since the basic point is that the main concerns in auctions are just the same as in other economic markets, so much of the same theory applies (see below). Furthermore, some of the key concerns are especially prominent when the assumption of symmetry is dropped, and models with asymmetries are often inelegant.

So graduate students are taught the elegant mathematics of affiliation and whenever, and wherever, I give a seminar about auctions in practice, ${ }^{22} \mathrm{I}$ am asked a question along the lines of "Haven't Milgrom and Weber shown that ascending auctions raise most revenue, so why consider other alternatives?". This is true of seminars to academics. It is even more true of seminars to policy makers. Thus, although a little knowledge of economic theory is a good thing, too much knowledge can sometimes be a dangerous thing. Moreover, the extraordinary influence of the concept of affiliation is only the most important example of this. I give a further illustration, involving overattention to some of my own work, in the next subsection. In short, a little graduate education in auction theory can often distract attention from the straightforward "undergraduate" issues that really matter. ${ }^{23}$

\section{The Elementary Economic Theory that Matters}

What really matters in practical auction design is robustness against collusion and attractiveness to entry - just as in ordinary industrial markets. ${ }^{24}$ Since I have repeatedly argued this, much of the material of this section is drawn from Klemperer (2000b, 2002a,

\footnotetext{
${ }^{22}$ I have done this in over twenty countries in five continents.

${ }^{23}$ True, the generally accepted notion of the "received auction theory" is changing and so is the auction theory that is emphasized in graduate programmes. And recent auctions research has been heavily influenced by practical problems. But it will probably remain true that the elegance of a theory will remain an important determinant of its practical influence.

${ }^{24}$ Of course, auction theorists have not altogether ignored these issues - but the emphasis on them has been far less. The literature on collusion includes Robinson (1985), Cramton, Gibbons, and Klemperer (1987), Graham and Marshall (1987), Milgrom (1987), Hendricks and Porter (1989), Graham, Marshall, and Richard (1990), Mailath and Zemsky (1991), McAfee and McMillan (1992), Menezes (1996), Weber (1997), Engelbrecht-Wiggans and Kahn (1998), Ausubel and Schwartz (1999), Brusco and Lopomo (1999), Hendricks, Porter, and Tan (1999) and Cramton and Schwartz (2000). That on entry includes Matthews (1984), Engelbrecht-Wiggans (1987), McAfee and McMillan (1987c), McAfee and McMillan (1988), Harstad (1990), Engelbrecht-Wiggans (1993), Levin and Smith (1994), Bulow and Klemperer (1996), Menezes and Monteiro (1997), Persico (1997), Klemperer (1998) and Gilbert and Klemperer (2000). See also Klemperer (1999, 2000a).
} 
2002b) and any reader familiar with these papers may wish to skip to section 4 .

\section{Entry}

The received theory described above takes the number of bidders as given. But the profitability of an auction depends crucially on the number of bidders who participate, and different auctions vary enormously in their attractiveness to entry; participating in an auction can be a costly exercise that bidders will only undertake if they feel they have realistic chances of winning. In an ascending auction a stronger bidder can always top any bid that a weaker bidder makes, and knowing this the weaker bidder may not enter the auction in the first place - which may then allow the stronger bidder to win at a very low price. In a first-price sealed-bid auction, by contrast, a weaker bidder may win at a price that the stronger bidder could have beaten, but didn't because the stronger bidder may risk trying to win at a lower price and can't change his bid later. So more bidders may enter a first-price sealed-bid auction. ${ }^{25}$

The intuition is very clear, and there is little need for sophisticated theory. Perhaps because of this, or because the argument depends on asymmetries between bidders so any theory is likely to be inelegant, theory has largely ignored the point. Vickrey's (1961) classic paper contains an example (relegated to an Appendix, and often overlooked) which illustrates the basic point that the player who actually has the lower value may win a first-price sealed-bid auction in Nash equilibrium, but that this cannot happen in an ascending auction (with private values). But little has been said since.

In fact, some of what has been written about the issue of attracting entry provides a further illustration of the potentially perverse impact of sophisticated theory. Although the point that weaker bidders are unlikely to win ascending auctions, and may therefore not enter them, is very general, some work - including Klemperer $(1998)^{26}$ - has emphasized that the argument is especially compelling for "almost-common-value" auctions, and this work may have had the unintended side-effect of linking the entry concern to common values in some peoples' minds $;{ }^{27}$ I have heard economists who know the latter work all too well say that because an auction does not involve common values, therefore there is no entry problem! ${ }^{28}$ To the extent that the almost-common values

\footnotetext{
25 The point is similar to the industrial-organization point that because a Bertrand market is more competitive than a Cournot market for any given number of firms, the Bertrand market may attract less entry, so the Cournot market may be more competitive if the number of firms is endogenous.

${ }^{26}$ See also Bikhchandani (1988), Bulow, Huang and Klemperer (1999), Bulow and Klemperer (2002), and Klemperer and Pagnozzi (2003).

27 in spite of the fact that I have made the point that the argument applies more broadly in, for example, Klemperer (1999b, 2002b). See also Gilbert and Klemperer (2000).

28 Similarly others have asserted (in spite of publicly-available government documents that show the contrary) that the reason the UK planned to include a sealed-bid component in its $3 \mathrm{G}$ design if only four
} 
theory (which is both of more limited application, and also assumes quite sophisticated reasoning by bidders) has distracted attention from the more general point, this is another example of excessive focus on sophisticated theory at the expense of more elementary, but more crucial, theory.

There is an additional important reason why a first-price sealed-bid auction may be more attractive to entrants: bidders in a sealed-bid auction may be much less certain about opponents' strategies, and the advantage of stronger players may therefore be less pronounced, than standard equilibrium theory predicts. The reason is that in practice, players are not likely to share common priors about distributions of valuations and, even if they do, they may not play Nash equilibrium strategies (that is, a sealed-bid auction induces "strategic uncertainty"). So even if players were in fact ex-ante symmetric (that is, their private information is drawn from identical distributions) the lower-value player might win a first-price sealed-bid auction, but would never win an ascending auction in which bidders' strategies are very straightforward and predictable. When players are not symmetric, Nash equilibrium theory predicts that a weaker player will sometimes beat a stronger player in a sealed-bid auction, but I conjecture strategic uncertainty and the absence of common priors make this outcome even more likely than Nash Equilibrium predicts. Since this point is very hard for standard economic theory to capture, it has largely been passed over. But it reinforces the point that a sealed-bid auction is in many circumstances more likely than an ascending auction to attract entry, and this will often have a substantial effect on the relative profitabilities of the auctions.

The 3G auctions provide good examples of over-sensitivity to the significance of information revelation and affiliation at the expense of insensitivity to the more important issue of entry. For example, the Netherlands sold five $3 \mathrm{G}$ licences in a context in which there were also exactly five incumbent mobile-phone operators who were the natural winners, leaving no room for any entrant. (For competition-policy reasons, bidders were permitted to win no more than one licence each). The problem of attracting enough entry to have a competitive auction should therefore have been uppermost in planners' minds. But the planners seem instead to have been seduced by the fact that ascending auctions raise (a little) extra revenue because of affiliation and also increase the likelihood of an efficient allocation to those with the highest valuations. ${ }^{29}$ The planners were probably also influenced by the fact that previous spectrum auctions in the U.S. and U.K. had used ascending designs, ${ }^{30}$ even though they had usually done so in contexts in which entry was

licences were available for sale (see below), was because the auction designers (who included me) thought the auction was almost-common values.

${ }^{29}$ It seems unlikely that the efficiency of the Netherlands auction was much improved by the ascending design.

${ }^{30}$ We discuss the U.K. design below. The design of the U.S. auctions, according to McMillan (1994, p.1512) who was a consultant to the FCC, was largely determined by faith in the linkage principle and hence in the revenue advantages of an ascending auction in the presence of affiliation. These advantages meant that the economic theorists advising the government judged other potential problems with the ascending design 
less of a concern, and even though some U.S. auctions did suffer from entry problems. The result of the Netherlands auction was both predictable, and predicted (see, for example, Maasland (2000) and Klemperer (2000b) quoted in the Dutch press prior to the auction). There was no serious entrant. ${ }^{31}$ Revenue was less than a third of what had been predicted and barely a quarter of the per capita amounts raised in the immediately preceding and immediately subsequent $3 \mathrm{G}$ auctions (in the U.K. and Germany respectively). The resulting furore in the press led to a Parliamentary Inquiry.

By contrast, when Denmark faced a very similar situation in its $3 \mathrm{G}$ auctions in late 2001 - four licences for sale and four incumbents - its primary concern was to encourage entry. ${ }^{32}$ (The designers had both observed the Netherlands fiasco, and also read Klemperer (2000b).) It chose a sealed-bid design (a "4th price" auction) and had a resounding success. A serious entrant bid, and revenue far exceeded expectations and was more than twice the levels achieved by any of the other three European $3 \mathrm{G}$ auctions (Switzerland, Belgium and Greece) that took place since late 2000.

The academics who designed the UK sale (which was held prior to the Netherlands and Danish auctions) also thought much harder about entry into their $3 \mathrm{G}$ auction. $^{33}$ The UK had four incumbent operators, and when design work began it was unclear how many licenses it would be possible to offer given the technological constraints. We realised that if there were just four licenses available it would be hard to persuade a non-incumbent to enter, so we planned in that case to use a design including a sealed-bid component (an "Anglo-Dutch" design) to encourage entry. In the event, five licenses were available so, given the UK context, we switched to an ascending auction, since there was considerable uncertainty about who the fifth strongest bidder would be (we ran the world's first 3G auction in part to ensure this — see Section 5). ${ }^{34} 13$ bidders

\footnotetext{
"to be outweighed by the bidders' ability to learn from other bids in the auction" (McMillan, 1994). (See also Perry and Reny (1999).) Efficiency was also a concern in the design of the U.S. auctions.

31 There was one entrant who probably did not seriously expect to win a license in an ascending auction indeed it argued strongly prior to the auction that an ascending auction gave it very little chance and, more generally, reduced the likelihood of entry into the auction. Perhaps it competed in the hope of being bought off by an incumbent by, e.g., gaining access rights to an incumbent's network, in return for its quitting the auction early. The Netherlands government should be very grateful that this entrant competed for as long as it did! See Klemperer (2002a) and van Damme (2002) for details.

${ }^{32}$ Entry was an even more severe problem in late 2001 than in early summer 2000 when the Netherlands auction was held. The dotcom boom was over, European telecoms stock prices at the time of the Danish auction were just one third the levels they were at in the Dutch auction, and the prospects for $3 \mathrm{G}$ were much dimmer than they had seemed previously.

33 I was the principal auction theorist advising the Radiocommunications Agency which designed and ran the U.K. auction. Ken Binmore had a leading role, including also supervising experiments testing the proposed designs. Other academic advisors included Tilman Borgers, Jeremy Bulow, Philippe Jehiel and Joe Swierzbinksi. Ken Binmore subsequently advised the Danish government on its very successful auction. The views expressed in this paper are mine alone.

${ }^{34}$ With five licenses, the licenses would be of unequal size, which argued for an ascending design. Note that in some contexts an ascending design may promote entry. For example, when Peter Cramton, Eric Maskin and I advised the U.K. government on the design of its March 2002 auction of reductions in
} 
entered, ensuring a highly competitive auction which resulted in the highest per capita revenue among all the European and Asian 3G auctions.

\section{Collusion}

The received auction theory also assumes bidders play non-cooperatively in Nash equilibrium. We have already discussed how Nash equilibrium may be a poor prediction because of "strategic uncertainty" and the failure of the common priors assumption, but a more fundamental problem is that players may behave collusively rather than noncooperatively. In particular, a standard ascending auction - especially a multi-unit ascending auction - often satisfies all the conditions that elementary economic theory tells us are important for facilitating collusion, even without any possibility of interaction or discussion among bidders beyond the information communicated in their bids.

For example, Waterson's (1984) standard industrial organization textbook lists five questions that must be answered affirmatively for firms to be able to support collusion in an ordinary industrial market: 1) Can firms easily identify efficient divisions of the market? 2) can firms easily agree on a division? 3) can firms easily detect defection from any agreement? 4) can firms credibly punish any observed defection? 5) can firms deter non-participants in the agreement from entering the industry? In a multi-unit ascending auction: 1) the objects for sale are well-defined, so firms can see how to share the collusive "pie" among them (by contrast with the problem of sharing an industrial market whose definition may not be obvious), 2) bids can be used to signal proposals about how the division should be made and to signal agreement, 3) firms' pricing (that is, bidding) is immediately and perfectly observable, so defection from any collusive agreement is immediately detected, 4) the threat of punishment for defection from the agreement is highly credible, since punishment is quick and easy and often costless to the punisher in a multi-object auction in which a player has the ability to raise the price only on objects that the defector will win, ${ }^{35}$ and 5) we have already argued that entry in an ascending auction may be hard.

\footnotetext{
greenhouse gas emissions, we recommended an ascending design to encourage the entry of small bidders for whom working out how to bid sensibly in a discriminatory sealed-bid auction might have been prohibitively costly. (Strictly speaking the auction was a descending one since the auction was a reverse auction in which firms were bidding to sell emissions reductions to the government. But this is equivalent to an ascending design for a standard auction to sell permits.) (Larry Ausubel and Jeremy Bulow were also involved in the implementation of this design.)

${ }^{35}$ For example, in a multi-license U.S. spectrum auction in 1996-97, U.S. West was competing vigorously with McLeod for lot number 378 - a license in Rochester, Minnesota. Although most bids in the auction had been in exact thousands of dollars, U.S. West bid $\$ 313,378$ and $\$ 62,378$ for two licenses in Iowa in which it had earlier shown no interest, overbidding McLeod, who had seemed to be the uncontested highbidder for these licenses. McLeod got the point that it was being punished for competing in Rochester, and dropped out of that market. Since McLeod made subsequent higher bids on the Iowa licenses, the "punishment" bids cost U.S. West nothing (Cramton and Schwartz, 2000).
} 
So collusion in an ascending auction seems much easier to sustain than in an "ordinary" industrial market, and it should therefore be no surprise that ascending auctions provide some particularly clear examples of collusion, as we illustrate below.

By contrast, a first-price sealed-bid auction is usually much more robust to collusion: bidders cannot "exchange views" through their bids, or observe opponents' bids until after the auction is over, or punish defection from any agreement during the course of the auction, or easily deter entry. But, perhaps because auction theorists have little that is new or exciting to say about collusion, too little attention has been given to this elementary issue in practical applications.

In the Austrian 3G auction, for example, twelve identical blocks of spectrum were sold to six bidders in a simultaneous ascending auction (bidders were allowed to win multiple blocks each). No-one was in the least surprised when the bidding stopped just above the low reserve price with each bidder winning two blocks, ${ }^{36}$ at perhaps one-third the price that bidders valued them at. ${ }^{37}$ Clearly the effect of "collusion" (whether explicit and illegal, or tacit and possibly legal) on revenues is first-order.

Another elegant example of bidders' ability to "collude" is provided by the 1999 German DCS-1800 auction in which ten blocks of spectrum were sold by ascending auction, with the rule that any new bid on a block had to exceed the previous high bid by at least 10 percent. $^{38}$ There were just two credible bidders, the two largest German mobile-phone companies T-Mobil and Mannesman, and Mannesman's first bids were 18.18 million deutschmarks per megahertz on blocks 1-5 and 20 million deutschmarks per MHz on blocks 6-10. T-Mobil - who bid even less in the first round - later said "There were no agreements with Mannesman. But [we] interpreted Mannesman's first bid as an offer." (Stuewe, 1999, p.13). The point is that 18.18 plus a 10 percent raise equals 20.00. It seems T-Mobil understood that if it bid 20 million deutschmarks per $\mathrm{MHz}$ on blocks $1-5$, but did not bid again on blocks 6-10, the two companies would then live and let live with neither company challenging the other on the other's half. Exactly that happened. So the auction closed after just two rounds with each of the bidders

\footnotetext{
${ }^{36}$ Although it did not require rocket science to determine the obvious way to divide twelve among six, the largest incumbent, Telekom Austria probably assisted the coordination when it announced in advance of the auction that it "would be satisfied with just two of the 12 blocks of frequency on offer" and "if the [5 other bidders] behaved similarly it should be possible to get the frequencies on sensible terms", but "it would bid for a third frequency block if one of its rivals did" (Crossland, 2000).

37 This extremely rough estimate is based on comparisons with other countries, allowing for changes in stock-market sentiment, etc., and is consistent with others' estimates. It is less than one-sixth the per capita price achieved three months earlier in the German auction.

${ }^{38}$ Unlike my other examples this was not a $3 \mathrm{G}$ auction; however, it is highly relevant to the German $3 \mathrm{G}$ auction which we will discuss.
} 
acquiring half the blocks for the same low price, which was a small fraction of the valuations that the bidders actually placed on the blocks. ${ }^{39}$

This example makes another important point. The elementary theory that tells us that "collusion" is easy in this context is important. The reader may think it obvious that bidders can "collude" in the setting described, but that is because the reader has been exposed to elementary undergraduate economic theory. This point was beautifully illustrated by the behaviour of the subjects in an experiment that was specifically designed to advise one of the bidders in this auction by mimicking its setting and rules: the experimental subjects completely failed to achieve the low-price "collusive" outcome that was achieved in practice. Instead "..... in [all] the [experimental] sessions the bidding was very competitive. Subjects went for all ten units in the beginning, and typically reduced their bidding rights only when the budget limit forced them to do so." (Abbink et al, 2002.) So the elementary economic theory of collusion which makes it plain, by contrast, that the "collusive" outcome that actually arose was to be expected from more sophisticated players does matter - and I feel confident that the very distinguished economists who ran the experiments advised their bidder more on the basis of the elementary theory than on the basis of the experiments. ${ }^{40}$

Both the U.K.'s and Denmark's academic advisors gave considerable thought to preventing collusion. Denmark, for example, not only ran a sealed-bid auction, but also allowed bidders to submit multiple bids at multiple locations with the rule that only the highest bid made by any bidder would count, and also arranged for phoney bids to be submitted - the idea was that bidders could not (illegally) agree to observe each others' bids without fear that their partners in collusion would double-cross them, and nor could bidders observe who had made bids, or how many had been made. ${ }^{41}$

\footnotetext{
${ }^{39}$ See Jehiel and Moldovanu, 2001, and Grimm, Riedel and Wolfstetter, 2001. Grimm et al argue that this outcome was a non-cooperative Nash equilibrium of the fully-specified game. This is similar to the familiar industrial organization point that oligopolistic outcomes that we call "collusive" may be Nash equilibria of repeated oligopoly games. But our focus is on whether outcomes look like competitive, noncooperative, behaviour in the simple analyses that are often made, not on whether or not they can be justified as Nash equilibria in more sophisticated models.

40 Abbink et al write "The lessons learnt from the experiments are complemented by theoretical strategic considerations". Indeed, auctions policy advice should always, if possible, be informed by both theory and experiments.

${ }^{41}$ In the U.K.'s ascending auction, the fact that bidders were each restricted to winning at most a single object, out of just five objects, ruled out tacit collusion to divide the spoils (provided that there were more than five bidders). More important, the large number of bidders expected (because the U.K. ran Europe's first $3 \mathrm{G}$ auction - see Section 5) also made explicit (illegal) collusion much less likely, (see Klemperer, 2002a) and the fact that the U.K. retained the right to cancel the auction in some circumstances also reduced bidders' incentive to collude.
} 


\section{Robustness to Political Pressures}

To be effective, economic advice must also be sensitive to the organizational and political context; it is important to be realistic about how advice will be acted on. Economic advisors commonly explain a policy failure with the excuse that "it would have been okay if they had followed our advice." But medical practitioners are expected to take account of the fact that patients will not follow their every instruction. ${ }^{42}$ Why should economic practitioners be different? Maybe it should be regarded as economic malpractice to give advice that will actually make matters worse if it is not followed exactly.

For example, the economic theorists advising the Swiss government on its $3 \mathrm{G}$ auction favoured a multi-unit ascending auction, apparently arguing along the standard received- auction-theory lines that this was best for both efficiency and revenue. But they recognised the dangers of such an auction encouraging "collusive" behaviour and deterring entry, and the advisors therefore also proposed setting a high reserve price. This would not only directly limit the potential revenue losses from collusion and/or inadequate entry but, importantly, also reduce the likelihood of collusion (with a high reserve price, bidders are relatively more likely to prefer to raise the price to attempt to drive their rivals out altogether, than to collude with them at the reserve price (see Klemperer, 2002b, and Brusco and Lopomo, 2002)).

But serious reserve prices are often unpopular with politicians and bureaucrats who - even if they have the information to set them sensibly - are often reluctant to run even a tiny risk of not selling the objects, which outcome they fear would be seen as "a failure".

The upshot was that no serious reserve was set. Through exit, joint-venture, and possibly - it was rumoured - collusion, ${ }^{43}$ the number of bidders shrank to equal the number of licences available, so the remaining bidders had to pay only the trivial reserve price that had been fixed. (Firms were allowed to win just a single licence each.) The

\footnotetext{
${ }^{42}$ Doctors are trained to recognize that some types of patients may not take all prescribed medicines or return for follow-up treatment. Pharmaceutical companies have developed one-dose regimens that are often more expensive or less effective than multiple-dose treatments, but that overcome these specific problems. For example, the treatment of chlamydial infection by a single dose of azithromycin is much more expensive and no more effective than a 7 day course of doxycycline; there is a short (2 month) course of preventive therapy for tuberculosis that is both more expensive, and seems to have more problems with side effects, than the longer 6 month course; and the abridged regimen for HIV+ women who are pregnant (to prevent perinatal transmission) is less effective than the longer, more extensive treatment.

43 Tele Danmark announced its acquisitions of Diax (an incumbent operator) and Sunrise (which was partly owned by BT) the day before the auction was due to begin, and a total of five bidders quit in the last four days before the auction. At least one bidder had quit earlier after hiring bidding consultants and hearing from them that because it was a weaker bidder it had very little chance of winning an ascending auction. Furthermore, the regulator investigated rumours that Deutsche Telekom agreed not to participate in the auction in return for subsequently being able to buy into one of the winners.
} 
outcome was met with jubilation by the bidders and their shareholders; per capita revenues were easily the lowest of any of the nine western European $3 \mathrm{G}$ auctions, and less than one-thirtieth of what the government had been hoping for. ${ }^{44,45}$ Perhaps an ascending auction together with a carefully chosen reserve price was a reasonable choice. But an ascending auction with only a trivial reserve price was a disaster, and the economic-theorist advisors should have been more realistic that this was a likely outcome of their advice. ${ }^{46}$

\section{Economic Similarity $\neq$ Political Similarity}

Hong Kong's auction was another case where designers should perhaps have anticipated the political response to their advice. The Hong Kong auction's designers, like Denmark's, had observed the Netherlands fiasco (and had also read Klemperer, 2000b). So they were keen to use a sealed-bid design, given Hong Kong's situation. ${ }^{47}$ Specifically, they favoured a "fourth-price" sealed-bid design so that all four winners (there were four licences and firms could win at most one licence each) would pay the same fourth-highest bid - charging winners different amounts for identical properties might both be awkward and lead to cautious bidding by managements who did not want to risk the embarrassment of paying more than their rivals. ${ }^{48}$

\footnotetext{
${ }^{44}$ The final revenues were 20 Euros per capita, compared to analysts' estimates of 400-600 Euros per capita in the week before the auction was due to begin, and a tiny fraction even of those achieved in Austria, whose auction was scheduled less than two weeks earlier. Meeks (2001) shows the jumps in Swisscom's share price around the auction are highly statistically-significant and, controlling for general market movements, correspond to the market believing that bidders paid several hundred Euros per capita less in the auction than was earlier anticipated.

${ }^{45}$ In fact, when the denouement of the auction had become clear, the Swiss government tried to cancel it and re-run it with different rules. But in contrast to the UK auction (see note $~ 32$ ), the designers had also omitted to allow themselves that possibility.

${ }^{46} \mathrm{I}$ am not arguing that an ascending auction plus reserve price is always bad advice, or even that it was necessarily poor advice here. But advisors must be very clear if success depends on a whole package being adopted, and should think carefully about the likely implementation of their proposals.

Greece and Belgium did set reserve prices that seem to have been carefully thought out, but they were perhaps encouraged to do so by the intense criticism of the Swiss auction, and also of the Italian and Austrian auctions which had reserve prices that were clearly too low, even if not as low as Switzerland's.

${ }^{47}$ In Hong Kong, unlike in the Netherlands and Denmark, there were actually more incumbents than licences. But it was not clear that all incumbents were strong. Furthermore, strong firms may form joint ventures (either legally or through illegal collusion) to reduce the number of entrants and this is much more attractive prior to a standard ascending auction (when the strengthened combined bidder further discourages entry) than prior to a standard sealed-bid auction (when reducing two strong bidders to one may attract entry).

In any case there was a very serious concern - well-justified as it turned out - that in a standard ascending auction there would be no more bidders than licences.

${ }^{48}$ In a simple model, if a winning bidder suffers "embarrassment costs" which are an increasing function of the difference between his payment and the lowest winning payment, then bidders are no worse off in expectation than in an auction which induces no embarrassment costs, but the auctioneer suffers. This is a consequence of the Revenue Equivalence Theorem: under its assumptions, mechanisms that induce
} 
However, the designers were also afraid that if the public could observe the top three bids after the auction, then if these were very different from the price that the firms actually paid (the fourth highest bid), the government would be criticised for selling the licences for less than the firms had shown themselves willing to pay. Of course, such criticism would be ill-informed, but it could still be damaging, because even wellintentioned commentators find it hard to explain to the general public that requiring firms to pay their own bids would result in firms bidding differently. Thus far, nothing was different from the situation in Denmark. However, whereas he Danish government simply followed the advice it was given to keep all the bids secret and reveal only the price paid, the Hong Kong government felt it could not do this.

Openness and transparency of government was a big political issue in the wake of Hong Kong's return to Chinese rule, and it was feared that secrecy would be impossible to maintain. The advisors therefore proposed to run an auction that was strategically equivalent (that is, has an identical game-theoretic structure and therefore should induce identical behaviour) to a fourth-price auction, but that did not reveal the three high bids to anyone. ${ }^{49}$ To achieve this, an ascending auction would be run for the four identical licences, but dropouts would be kept secret and the price would continue to rise until the point at which the number of players remaining dropped from four to three. At this point the last four (including the firm that had just "dropped out") would pay the last price at which four players remained in the bidding. Since nothing was revealed to any player until the auction was over, no player had any decision to make except to choose a single dropout price, in the knowledge that if its price was among the top four then it would pay the fourth-highest dropout price; that is, the situation was identical from the firm's viewpoint to choosing a single bid in a fourth-price sealed-bid auction. But, unlike in Denmark, no one would ever see the "bids" planned by the top three winners (and since these bids would never even have been placed, very little credibility would have attached to reports of them).

However, although the proposed auction was mathematically (i.e., strategically) equivalent to a sealed-bid auction, its verbal description was very different. The stronger incumbents lobbied vigorously for a "small change" to the design - that the price be determined when the numbers dropped from five to four, rather than from four to three.

embarrassment costs cannot affect bidders' utilities (it is irrelevant to the bidders whether the "embarrassment costs" are received by the auctioneer or are social waste), so in equilibrium winning bidders' expected payments are lower by the expected embarrassment costs they suffer. See Klemperer (2002e).

49 I had no direct involvement with this auction but, embarrassingly, I am told this "solution" was found in a footnote to Klemperer (2000b) that pointed out this method of running a strategically equivalent auction to the uniform fourth-price auction, and that it might (sometimes) be more politically acceptable. See also Binmore and Klemperer (2002). 
This is the "standard" way of running an ascending auction, and it recreates the standard problem that entry is deterred because strong players can bid aggressively in the knowledge that the winners will only pay a loser's bid (the fifth bid) and not have to pay one of the winners' bids.

Revealingly, one of the strong players that, it is said, lobbied so strongly for changing the proposal was at the same time a weaker player (a potential entrant) in the Danish market and, it is said, professed itself entirely happy with the fourth-price sealedbid rules for that market.

Since the change the firms lobbied for seemed to make things more "standard", and seemed small (and perhaps not all the decision-makers understood - or wanted to understand - its larger significance), the government gave way and made it. ${ }^{50,51}$

The result? Just four bidders entered and paid the reserve price - a major disappointment for the government, and yielding perhaps one third to one half the revenue that had been anticipated (correcting for market conditions). Whether other potential bidders gave up altogether, or whether they made collusive agreements with stronger bidders not to enter (as was rumoured in the press), is unknown. But what is certain is that the design finally chosen made entry much harder and collusion much easier.

It is not clear what the economic theorists advising should have recommended. Perhaps they should have stuck to a (fourth-price) sealed-bid auction run in the standard way, but used computer technology that could determine the price to be paid while making it impossible for anyone other than the bidders to know the other bids made.

The moral, however, is clear. Auction designs that seem similar to economic theorists may seem very different to politicians, bureaucrats and the public, and viceversa. And political and lobbying pressures need to be predicted and planned for in advance.

When the designers of the U.K. 3G auction proposed a design - the Anglo-Dutch - that was very unattractive to the incumbent operators, it probably helped that two alternative versions of the design were initially offered. Whilst the incumbent operators hated the overall design and lobbied furiously against it, ${ }^{52}$ they also had strong

\footnotetext{
${ }^{50}$ Not only was the change argued to be "small", and to make the auction more "standard", but it was also argued that it was "unfair" to have the bidders continue to bid against themselves when there were just four left. These points were all politically salient, even though they are irrelevant or meaningless from a strictly game-theoretic viewpoint. Moreover, the academic consultants who proposed the original design to the committee responsible for the auction details had very little influence at the higher political levels at which the final decision was taken.

51 The highly sophisticated security arrangements that had been made to ensure secrecy of the dropouts (removal of bidding teams to separate top-secret locations in army camps, etc.) were not altered even though they had become much less relevant; there was no need to lobby against these.

${ }^{52}$ It is rumoured that a single bidder's budget for economic advice for lobbying against the design exceeded the U.K. government's expenditure on economic advice during the entire three-year design process; the
} 
preferences between its two versions, and much of their lobbying efforts therefore focused on the choice between them. When the government selected the version the operators preferred (the designers actually preferred this version too) the operators felt they had got a part of what they had asked for, and it proved politically possible for the government to stick to the Anglo-Dutch design until the circumstances changed radically. 53

Another notorious "political failure" was the design of the 1998 Netherlands 2G spectrum auction. The EU Commission objected to the Netherlands government's rules for the auction shortly before the (EU imposed) deadline for the allocation of the licences. The rules were therefore quickly rewritten by a high-ranking civil servant on a Friday afternoon. The result was an auction that sold similar properties at prices that differed by a factor of about two, and almost certainly allocated the licences inefficiently (van Damme, 1999). ${ }^{54}$

Economists are now waking up to the importance of these issues: Wilson (2002) addresses political constraints in the design of auction markets for electricity, and Roth (2002) also discusses political aspects of market design. But the politics of design remains understudied by economic theorists, and underappreciated by them in their role as practitioners.

\section{Understanding the Wider Context}

Any consultant new to a situation must beware of overlooking issues that are well understood by those with more experience of the environment. The danger is perhaps particularly acute for economic theorists who are used to seeing the world through models that, while very elegant, are often lacking in real-world detail and context.

The German 3G auction illustrates the importance of the wider context. As we described in section 3, in Germany's 1999 DCS-1800 auction Mannesman used its bids to

lobbying effort included hiring two Nobel prize winners in the hope of finding arguments against the design. See Binmore and Klemperer (2002) for details of the two versions of the design.

${ }^{53}$ When it became possible to offer an additional fifth licence in the U.K. the design changed - as had been planned for this circumstance - to a pure ascending one, see Section 3.

${ }^{54}$ This auction also illustrates that errors made by bidders can be important in determining the outcomes of small-numbers auctions: although high stakes were involved (the revenues were over 800 million euros) it seems that the outcome, and perhaps also the efficiency of the allocation of licences, was critically affected by a bidder unintentionally losing its eligibility to bid on additional properties later in the auction; it has been suggested that this bidder's behavior can only be explained by the fact that it happened on "Carnival Monday", a day of celebrations and drinking in the south of the Netherlands where the bidder is based (van Damme, 1999)! (The German 3G auction described below provides another example of the large role that bidder error can play, though in this case it only affected the auction's revenue and not the efficiency of the allocation of licenses.) 
signal very clearly to T-Mobil how the two firms should divide the blocks between them and end the auction at a comparatively low price. T-Mobil then cut back its demand in exactly the way Mannesman suggested, and Mannesman followed through with its half of the "bargain" by also cutting back its demand, so the auction ended with the two firms winning similar amounts of spectrum very cheaply.

It seems that Mannesman used the same advisors in the $3 \mathrm{G}$ auction that it had used in the GSM auction. Although the rules for the $3 \mathrm{G}$ auction were not identical, it was another simultaneous ascending auction in which individual bidders were permitted to win multiple blocks. After the number of bidders had fallen to six competing for a total of twelve blocks, and when it was clear that the other four bidders would be content with two blocks each, Mannesman apparently signalled to T-Mobil to cut back its demand to just two blocks. ${ }^{55}$ If T-Mobil and Mannesman had both done this the auction would have ended at modest prices. Instead T-Mobil seemingly ignored Mannesman's signals, and drove up the total price 15 billion Euros before cutting back demand. Once T-Mobil did cut back its demand, Mannesman followed, so the auction ended with the allocation that Mannesman had originally signalled but with each of the six firms paying an additional $2 \frac{1}{2}$ billion Euros! It seems that Mannesman's advisors saw the GSM auction as a template for the $3 \mathrm{G}$ auction; they took the view that, following previous practice, Mannesman would signal when to reduce demand, T-Mobil would acquiesce, and Mannesman would then follow through on its half of the bargain. ${ }^{56}$ The bargain would be enforced by firms not wishing to jeopardise their future cooperation in subsequent auctions (including 3G auctions in other countries) and in negotiating with regulators, etc. (and the short-run advantage that could be gained by failing to cooperate was anyway probably small, see Klemperer, 2002c). But given their expectation that T-Mobil would cut back demand first, Mannesman's advisors were unwilling to reduce demand when TMobil did not.

Clearly, T-Mobil's advisors saw things differently. It seems that their main advisors had not been involved in the GSM auction and the example of the previous auction was certainly not in the forefront of their minds. Instead they mistrusted Mannesman's intentions, and were very unwilling to cut back demand without proof that Mannesman had already done so. True the $3 \mathrm{G}$ auction was a much more complicated game than the GSM auction because of the other parties involved, and Klemperer (2002c)

\footnotetext{
55 According to the Financial Times, "One operator has privately admitted to altering the last digit of its bid... to signal to other participants that it was willing to accept a small licence." 3/11/2000, p21.

${ }^{56}$ It seems that another reason why Mannesman expected the firms to coordinate by T-Mobil reducing demand first in response to Mannesman's signals was that Mannesman saw itself as the leading firm in the market. In fact, T-Mobil might have argued about whether Mannesman was the leading firm - the two firms were closely matched - and this may have been part of the problem. But Mannesman certainly saw itself as the leader, and this was also the view of, e.g., Abbink et al (2002).
} 
discusses other factors that may have contributed to the firms' failure to reduce demand. ${ }^{57}$ But T-Mobil's refusal to cut back demand very likely stemmed partly from viewing the $3 \mathrm{G}$ auction in a different, and narrower, context than Mannesman did.

Just as previous auctions within any country might have been an important part of the wider context, auctions in other countries are also relevant parts of the broader environment: the sequencing of the $3 \mathrm{G}$ auctions across countries was crucial. Countries that auctioned earlier had more entrants, because weaker bidders had not yet worked out that they were weaker and quit the auctions, because stronger bidders had not yet worked how and with whom to do joint ventures, and because complementarities between the values of licences in different countries reinforced these effects - the number of entrants in the nine western European auctions were (in order) 13, 6, 7, 6, 6, 4, 3, 3, and 5 respectively. ${ }^{58}$ Countries that auctioned earlier also suffered less from "collusive" behaviour, because bidders had had less practice in learning how best to play the game. For example, when the Austrian 3G auction followed the German 3G auction that we have just described, using almost the same design, all the bidders very quickly saw the mutual advantage of coordinating a demand reduction (see Section 3). ${ }^{59}$

The U.K. government's advisers anticipated this pattern of declining competition, and chose to run its auction first; indeed we persisted in the policy of running the first auction even when others were advising us to delay (see Binmore and Klemperer, 2002). Yet in more than one country auction theorists advising on $3 \mathrm{G}$ auction design seemed either unaware of (!), or at least unaffected in their thinking by, the fact that there was to be a sequence of auctions across Europe. Clearly these designers had far too narrow a view of the problem. ${ }^{60}$

Of course, other auctions are only the most obvious aspects of the wider context that auction designers need to consider. There are many other ways in which designers showed themselves very poor at thinking about the wider game. For example, many of the $3 \mathrm{G}$ auction designers had a very limited understanding of how the auction process affected, and was affected by, the series of telecom mergers and alliances that the advent

\footnotetext{
57 In particular, the firms might have been concerned about their relative performances. See also Grimm et al (2002), Jehiel and Moldovanu (2002), and Ewerhart and Moldovanu (2002).

${ }^{58}$ Furthermore, the number (6) achieved in the second auction (Netherlands) was perhaps lowered by the peculiarly incompetent design; the number (5) achieved in the last auction (Denmark) was raised by its design, which was very skilful except in its timing - see section 3 .

Of course, other factors, in particular the fall in the telecoms stock price index, may have contributed to the fall in the number of entrants.

59 Klemperer (2002a) develops the arguments in this paragraph in much more detail.

60 Some of the incumbent bidders, by contrast, may possibly have had a clearer understanding. In an interesting example of the importance of political pressures, the Dutch operators successfully lobbied to delay the Netherlands auction and the clear gap that was thereby created between the British and Dutch auctions may have been a contributory factor to the Dutch fiasco.
} 
of $3 \mathrm{G}$ engendered - in the U.K. alone, there were no fewer than five mergers involving the four incumbent $2 \mathrm{G}$ operators, in less than a year around the auction. ${ }^{61}$

\section{Using Economic Theory}

I have argued that while a good understanding of elementary undergraduate economic theory is essential to successful auction design, advanced graduate auction theory is often less important. It is important to emphasise, therefore, the crucially important role that advanced formal theory plays in developing our economic understanding. In particular, advanced theory often develops deeper connections between apparently distinct economic questions than are superficially apparent.

For example, Klemperer (forthcoming) demonstrates that auction-theoretic tools provide useful arguments in a broad range of mainstream economic contexts. As a further illustration, I will discuss how a part of the received auction theory - the effect of affiliation - that was, I have argued, not central to the auctions of $3 \mathrm{G}$ licences, can develop useful insights about the economics of the "M-Commerce" industry that $3 \mathrm{G}$ will create. $^{62}$

\section{Do E-commerce and M-commerce raise consumer prices?}

Some commentators and regulators have expressed concern that e-commerce and M-commerce ("mobile commerce" in which people purchase through their mobile phones, and which is predicted to expand rapidly as a result of $3 \mathrm{G}$ technology) allow firms to easily identify and collect information about their customers which they can use to "rip them off". ${ }^{63}$

A simple analysis realizes that each consumer is analogous to an auctioneer, while firms are bidders competing to sell to that consumer. As we discussed in Section 2, bidders' expected profits derive from their private information, and the auctioneer generally gains by reducing the amount of bidders' private information. So if all firms learn the same piece of information about a given consumer, this (weakly) reduces the

\footnotetext{
${ }^{61}$ Klemperer (2002d) gives another illustration of how real-world context that was non-obvious to outsiders was important to the UK $3 \mathrm{G}$ auction.

62 Klemperer (forthcoming) uses the other main piece of the received auction theory - the Revenue Equivalence Theorem - to solve a war of attrition between several technologies competing to become an industry standard in, e.g., 3G (see also Bulow and Klemperer, 1999) and to compute the value of new customers to firms when consumers have switching costs as they do for e.g., 3G phones (see also Bulow and Klemperer, 1998). Klemperer (forthcoming) also uses auction theory to address how e-commerce (and likewise M-commerce) affects pricing.

63 The US Federal Trade Commission has held hearings on this issue, and the European Commission is currently studying it. Amazon has admitted charging different prices to different consumers.
} 
private information that any bidder has relative to the other bidders, and so often benefits the auctioneer, that is, lowers the consumer's expected transaction price.

Although this result is a good start, it is neither very novel, ${ }^{64}$ nor does it address the bigger concern that e-and M-commerce allow different firms to learn different information about any given consumer. However, Bulow and Klemperer (forthcoming) show how to use the mathematics of affiliation to address this issue too; in our model, even if firms learn different information about the consumers, this makes the market more competitive. In other words, a quick application of Milgrom and Weber's (1982) analysis suggests that the "loss of privacy" caused by $3 \mathrm{G}$ and the internet is actually good for consumers.

Of course, having been cautious about the practical significance of affiliation in auction design, we should also be cautious about asserting that Bulow and Klemperer's argument shows that $3 \mathrm{G}$ is not as valuable to firms as some people once thought. ${ }^{65}$ However, our model suggests a possibility which needs further study - including considering any empirical evidence and the plausibility of the intuitions - to confirm or disconfirm. Moreover, it certainly demonstrates that just because firms learn more about consumers, it does not follow that they can exploit them better - just as the RET refutes any simple presumption that one form of auction is always the most profitable. Our analysis therefore shows that firms' learning has other effects in addition to the very obvious one that firms can price-discriminate more effectively, and it helps us to see what these effects are ${ }^{66}$ - we can then consider further whether these effects are plausibly significant. It also provides a structure which suggests what other factors not in the simplest model might in fact be important, and might perhaps yield the originallyhypothesised result. ${ }^{67}$ And it very quickly and efficiently yields results that provide a good starting point for such further analysis.

\footnotetext{
${ }^{64}$ Thisse and Vives (1988), Ulph and Vulkan (2001), and Esteves (forthcoming), for example, have developed similar results.

${ }^{65}$ Of course, there are more important reasons why $3 \mathrm{G}$ is no longer thought as valuable as it once was (see Klemperer, 2002a).

${ }^{66}$ In this case, while a firm may raise prices against consumers who particularly value its product, in a competitive environment it will also lower prices to other consumers who like it less - and other firms will then have to respond.

${ }^{67}$ For example, the analysis shows that even though it may be no bad thing for consumers if different firms learn different pieces of information about them, the result depends on firms learning the same amount of information about any given consumer. It probably is costly for a consumer to "lose his privacy" to only one firm, just as having asymmetrically informed bidders may be a bad thing for an auctioneer. Furthermore, even when firms learn the same amount of information about consumers' tastes, this information may sometimes lead to inefficient price-discrimination which reduces total welfare, in which case consumers may be made worse off even though firms' profits are lowered, just as inefficient auctions may be bad for both auctioneers and bidders. Learning information may also affect firms' abilities to collude, and the ease of new entry.
} 
Bulow and Klemperer pursue these issues in the context of this specific application. Klemperer (forthcoming) considers a range of other applications, including some that at first glance seem quite distant from auctions. The moral is that the "received auction theory" is of great value in developing our understanding of practical issues. But it needs to be used in conjunction with developing intuition and gathering empirical evidence to check its applicability to specific situations.

\section{Conclusion}

This paper is not attacking the value of economic theory. I have argued that elementary economic theory is essential to successful economic policy. Furthermore, the methods of thinking that undergraduate economics teaches are very valuable, for example, in understanding the important distinction between Hong Kong's two superficially similar auction designs (the one proposed and the one actually implemented). This essay has focused on examples from auctions, but the more I have been involved in public policy (for example, as a Member of the U.K. Competition Commission), the more I have been impressed by the importance of elementary undergraduate economics.

Nor is this paper intended as an attack on modern, or sophisticated, or graduate economics. True, the emphasis of some graduate courses is misleading, and the relative importance of different parts of the theory is not always well-understood, but almost all of it is useful when appropriately applied; it is not true that all economic problems can be tackled using undergraduate economics alone. ${ }^{68}$

Policy errors are also less likely when expertise is not too narrowly focused in one subdiscipline - for example, auction designers should remember their industrial economics and political economy (at least) in addition to pure auction theory.

While advanced theory can be misapplied, the correct answer is not to shy away from it, but rather to develop it further to bring in the important issues that have been omitted. It may sometimes be true that "a little bit too much economics is a dangerous thing", but it is surely also true that a great deal of economic knowledge is best of all. Moreover auction theory also illustrates that when a subdiscipline of economics becomes more widely used in practical policy making, its development becomes more heavily influenced by the practical problems that really matter. Like a rapidly growing bush, theory may sometimes sprout and develop in unhelpful directions, but when pruned with the shears of practical experience it will quickly bear fruit!

\footnotetext{
${ }^{68}$ Furthermore, it is often only the process of thinking through the sophisticated graduate theory that puts the elementary undergraduate theory in proper perspective.
} 
Furthermore, advanced economic theory is of practical importance in developing our economic understanding of the world, even when it cannot be directly applied to an immediate practical problem. To recapitulate only the incomplete list of its merits that was illustrated by our example in section 6 , it refutes over-simple arguments, makes precise and quantifies other arguments, allows us to see the relationship between superficially unconnected problems, organises our ideas, brings out the important features of problems, shows possibilities, and quickly develops general results which, even when they are not final answers, provide good starting points for further analysis.

Nevertheless, the main lesson of this paper is that the blinkered use of economic theory can be dangerous. Policy advisers need to learn from Marshall's example to beware of the wider context, anticipate political pressures and, above all, remember that the most sophisticated theory may not be the most relevant.

\section{References (Will be put in consistent style later!)}

Abbink, K., B. Irlenbusch, B. Rockenbach, A. Sadrieh, and R. Selten (2002) The behavioural approach to the strategic analysis of spectrum auctions: the case of the German DCS-1800 auction, Working Paper, Universities of Nottingham, Erfurt, Tilburg, and Bonn.

Ausubel, Lawrence M. and Jessie A. Schwartz. 1999. “The Ascending Auction Paradox.” Working paper, University of Maryland.

Bikhchandani, S., 1988. "Reputation in Repeated Second-price Auctions." Journal of Economic Theory 46, 97-119.

Binmore, K., Klemperer, P., 2002. "The Biggest Auction Ever: the Sale of the British 3G Telecom Licences." Economic Journal, 112(478), C74-C96

Brusco, Sandro and Giuseppe Lopomo. 1999. "Collusion via Signalling in Open Ascending Auctions with Multiple Objects and Complementarities.” Working Paper, Stern School of Business, New York University.

Brusco, Sandro and Giuseppe Lopomo. 2002. "Simultaneous Ascending Auctions with Budget Constraints." Working Paper, Stern School of Business, New York University.

Bulow, Jeremy I., Huang, M., Klemperer, Paul, 1999. "Toeholds and Takeovers." Journal of Political Economy, 107, 427-454. (also reprinted in New Research in Corporate Finance and Banking, Biais and M. Pagano (eds.), Oxford University Press, 2002, 91-116).

Bulow, Jeremy, Klemperer, Paul, (1996) "Auctions vs. Negotiations." American Economic Review, 86(1), 180-194.

Bulow, Jeremy, Klemperer, Paul, (1998) “The Tobacco Deal” Brookings Papers on Economic activity: Microeconomics 1998, 323-94.

Bulow, Jeremy, Klemperer, Paul, (1999) The Generalized War of Attrition. American Economic Review, 89, 175-189. 
Bulow, Jeremy, Klemperer, Paul, (2002) "Prices and The Winner's Curse." Rand Journal of Economics, 33(1), 1-21.

Bulow, Jeremy, Klemperer, Paul (forthcoming) "Privacy and Pricing” Nuffield College, Oxford University Discussion Paper.

Clark, Colin (1939) "The conditions of Economic Progress." Brisbane, Australia.

Cramton, Peter, Gibbons, R., Klemperer, Paul, 1987. "Dissolving a Partnership Efficiently." Econometrica, $55,615-32$.

Cramton, P and Schwartz, J. A., 2000. "Collusive Bidding: Lessons from the FCC Spectrum Auctions." Journal of Regulatory Economics, 17:3. pp. 229-52.

Crossland, D., 2000. "Austrian UMTS Auction Unlikely to Scale Peaks." Reuters. October 31. Available at (http://www.totaltele.com).

Engelbrecht-Wiggans, R. (1987) Optimal Reservation Prices in Auctions. Management Science, 33, 763 70.

Engelbrecht-Wiggans, R. (1993) Optimal Auctions Revisited. Games and Economic Behaviour, 5, $227-39$.

Engelbrecht-Wiggans, Richard and Charles M. Khan. 1998. "Low Revenue Equilibria in Simultaneous Auctions." Working paper, University of Illinois.

Esteves, R. "Targeted Advertising and Price Discrimination in the New Media: ". forthcoming, DPhil thesis, Oxford University.

Ewerhart, C., and Moldovanu, B., "The German UMTS Design: Insights from Multi-Object Auction Theory", ifo Studien, 48(1), 158-174.

Friedman, Milton, Essays in Positive Economics, Chicago: University of Chicago Press, 1953.

Gilbert, R. and Klempere r, P. D. (2000) An Equilibrium Theory of Rationing. Rand Journal of Economics, 31(1), 1-21.

Graham, D. A. and Marshall, R. C. (1987) Collusive Bidder Behavior at Single-Object Second-Price and English Auctions. Journal of Political Economy, 95, 1217-39.

Graham, D. A., Marshall, R. C., and Richard, J-F. (1990) Differential Payments within a Bidder Coalition and the Shapley Value. American Economic Review, 80, 493-510.

Grimm, V., Riedel F., and Wolfstetter, E., 2001. "Low Price Equilibrium in Multi-Unit Auctions: The GSM Spectrum Auction in Germany." Working Paper, Humboldt Universität zu Berlin.

Grimm, V., Riedel F., and Wolfstetter, E., 2002, “The Third Generation (UMTS) Spectrum Auction in Germany", ifo Studien, 48(1), 123-143.

Haile, P., 1996. "Auctions with Resale Markets". PhD dissertation. Northwestern University.

Hansen, R.G., 1986. "Sealed Bids versus Open Auctions: The Evidence." Economic Inquiry, 24, pp.12542.

Harstad, R. M. (1990) Alternative Common Values Auction Procedures: Revenue Comparisons with Free Entry. Journal of Political Economy, 98, 421-29. 
Hendricks, K. and Porter, R. H. (1989) Collusion in Auctions. Annales D'Économie et de Statistique, 15/16, 217-30.

Hendricks, K., Porter, R. H., and Tan, G. (1999) Joint Bidding in Federal Offshore Oil and Gas Lease Auctions. Working Paper, University of British Columbia.

Jehiel, P., and Moldovanu, B., 2001. "The UMTS/IMT-2000 License Auctions." Working Paper, University College London, and University of Mannheim.

Jehiel, P., and Moldovanu, B., 2002, “An Economic Perspective on Auctions”, Working Paper, University College London, and University of Mannheim.

Kagel, J. H., and Roth, A. E.(eds.), 1995. "The Handbook of Experimental Economics." Princeton University, Princeton, New Jersey.

Keynes, J. M., 1933. "Essays in Biography", Macmillan and Co., Ltd, London.

Klemperer, P., 1998. "Auction with Almost Common Values." European Economic Review, 42(3-5), 757 769.

Klemperer, P., 1999. "Auction Theory: A Guide to the Literature." Journal of Economic Surveys, 13(3), 227-286. [Also reprinted in The Current State of Economic Science, (1999). S. Dahiya, ed. 2, 711-766.]

Klemperer, P., 1999b. "Applying Auction Theory to Economics." Invited Lecture to Eighth World Congress of the Econometric Society, at www.paulklemperer.org.

Klemperer, P., 2000a. "The Economic Theory of Auctions " (ed.). Cheltenham, U.K.: Edward Elgar.

Klemperer, P., 2000b. "What Really Matters in Auction Design." May 2000 version, at www.paulklemperer.org.

Klemperer, P., 2002a. "How (Not) to Run Auctions: the European 3G Telecom Auctions." European Economic Review, 46(4-5), 829-845.

Klemperer, P., 2002b. "What Really Matters In Auction Design." Journal of Economic Perspectives, 16(1), 169-189.

Klemperer, P., 2002c. "Some observations on the German 3G telecom auction." ifo Studien, 48(1), 145 156, and at www.paulklemperer.org.

Klemperer, P., 2002d. "Some observations on the British 3G telecom auction." ifo Studien, 48(1), 115 120 , and at www.paulklemperer.org

Klemperer, P., 2002e. examination question x, at www.paulklemperer.org.

Klemperer, P., 2003. "Why Every Economist Should Learn Some Auction Theory." In: M. Dewatripont, L. Hansen, S. Turnovsky, (eds.), Advances in Economics and Econometrics: Invited Lectures to Eighth World Congress of the Econometric Society, Cambridge, UK: Cambridge University Press, and at www.paulklemperer.org.

Klemperer, P., and Pagnozzi, M., 2003. "Advantaged Bidders and Spectrum Prices: An Empirical Analysis." Forthcoming at www.paulklemperer.org.

Levin, D., Kagel, J. H., and Richard, J-F., "Revenue Effects and Information Processing in English Common Value Actions". American Economic Review, vol.86 (3) p. 442-460. 
Levin, D. and Smith, J. L. (1994) Equilibrium in Auctions with Entry. American Economic Review, 84, 585-99.

Maasland, E., 2000. "Veilingmiljarden Zijn een Fictie (Billions from Auctions: Wishful Thinking)." ESB June 9: p. 479 and translation available at www.paulklemperer.org.

Machlup, F., Marginal Analysis and Empirical Research”, American Economic Review 36 (Sept. 1946), 519-54.

Mailath, G. J. and Zemsky, P. (1991) Collusion in Second Price Auctions with Heterogeneous Bidders. Games and Economic Behavior, 3, 467-86.

Marshall, Alfred, 1890. "Principles of Economics", Macmillan \& Co., Ltd. London.

Marshall, Alfred, 1906. Letter to A. L. Bowley, February 27, 1906, in A. C. Pigon (ed) Memorials of Alfred Marshall Macmillan: London (1925) pp427-428.

Maskin, E. S. and Riley, J. G. (1984) Optimal Auctions with Risk Averse Buyers. Econometrica, 52, 1473 1518.

Maskin, E. S. and Riley, J. G. (2000) Asymmetric Auctions. Review of Economic Studies. Vol. 67, pp. 413-439

Matthews, S. A. (1983) Selling to Risk Averse Buyers with Unobservable Tastes. Journal of Economic Theory, 3, 370-400.

Matthews, S. A.(1984) Information Acquisition in Discriminatory Auctions. In M. Boyer and R. E. Kihlstrom (eds.), Bayesian Models in Economic Theory (pp. 181-207). New York: North Holland.

McAfee, R. P. and McMillan, J. (1987c) Auctions with Entry. Economics Letters, 23, 343-47.

McAfee, R. P. and McMillan, J. (1988) Search Mechanisms. Journal of Economic Theory, 44, 99-123.

McAfee, R. P and McMillan, J. (1992) Bidding Rings. American Economic Review, 82, 579-99.

McMillan, J. (1994) Selling Spectrum Rights. Journal of Economic Perspectives, 8, 145-62.

Mead, W. J., and Schneipp, M., 1989. "Competitive bidding for federal timber in region

6, An update: 1983-1988." Community and Organization Research Institute, University of California, Santa Barbara.

Meeks, R., 2001. "An Event Study of the Swiss UMTS Auction." Research Note, Nuffield College, Oxford University.

Menezes, Flavio. (1996). "Multiple-unit English auctions.” European Journal of Political Economy. 12, pp. 671-684.

Menezes, F. M. and Monteiro, P. K. (1997) Auctions with Endogenous Participation. Mimeo, Australian National University and IMPA.

Milgrom, P. R. (1987) Auction Theory. In Truman F. Bewley (ed.), Advances in Economic Theory: Fifth World Congress. Cambridge: Cambridge University Press.

Milgrom, P. R., and Weber. R. J., 1982. "A Theory of Auctions and Competitive Bidding." Econometrica, 50, pp. 1089-1122. 
Milgrom, P. R., and Weber, R. J., 2000. In Klemperer. (ed.), The Economic Theory of Auctions, Cheltenham, U.K.: Edward Elgar.

Myerson, R. B. (1981) Optimal Auction Design. Mathematics of Operations Research, 6, 58-73.

Paarsch, Harry J. 1991. "Empirical Models of Auctions and an Application to British Columbian Timber Sales.” University of British Columbia Discussion Paper.

Perry, Motty and Reny, Philip J. 1999. "The Failure of the Linkage Principle in Multi-Unit Auctions." Econometrica, 67(4) pp. 895-900.

Persico, N. (1997) Information Acquisition in Auctions. Working Paper, U.C.L.A.

Riley, J. G., and H Li., 1997. "Auction Choice: A Numerical Analysis." Mimeo, University of California at Los Angeles.

Riley, J. G. and Samuelson, W. F. (1981) Optimal Auctions. American Economic Review, 71, 381-92.

Robinson, M. S. (1985) Collusion and the Choice of Auction. Rand Journal of Economics, 16, 141-45.

Roth, Alvin E., 2002. "The Economist as Engineer: Game Theory, Experimentations, and Computation as Tools for Design Economics.” Econometrica, vol. 70, no. 4 - July, pp. 1341-1378.

Rothkopf, M. H., and Engelbrecht-Wiggans., R., 1993. "Misapplications Reviews: Getting the Model Right---The Case of Competitive Bidding." Interfaces, 23, pp. 99-106.

Sills, David L.(ed.), 1968. International Encyclopedia of the Social Sciences, Macmillan Company and The Free Press, vol. 10.

Stuewe, H., 1999. "Auktion von Telefonfrequenzen: Spannung bis zur letzten Minute." Frankfurter Allgemeine Zeitung, October 29.

Thisse, J., and Vives, X., 1988. "On the Strategic Choice of Spatial Price Policy". American Economic Review, 78, 122-137.

Ulph, D., and Vulkan, N., 2001. "E-Commerce, Mass Customisation and Price Discrimination", mimeo, UCL and University of Bristol.

van Damme, E., 1999. “The Dutch DCS-1800 Auction”, in Game practise: contributions from applied game theory, Fioravante Patrone, Ignacio Garcia-Jurado, Stef Tijs (eds.), pp. 53-73, Kluwer Academic Publisers.

van Damme, E., 2002. "The European UMTS Auctions". European Economic Review, 45(4-5), 846-858.

Vickrey, W., 1961. "Counterspeculation, Auctions, and Competitive Sealed Tenders." Journal of Finance, 16 , pp. 8-37.

Waterson, M., 1984. Economic Theory of the Industry. Cambridge University Press: Cambridge, U.K.

Weber, Robert J. 1997. "Making More from Less: Strategic Demand Reduction in the FCC Spectrum Auctions." Journal of Economics and Management Strategy. 6:3, pp. 529-48.

Wilson, Robert (2002). “Architecture of Power Markets.” Econometrica, 70(4) - July, 1299-1340. 